\title{
Correction to: Optimal image compression via block-based adaptive colour reduction with minimal contour effect
}

\author{
Pejman Rasti ${ }^{1}$ - liris Lüsi ${ }^{2}$ - Anastasia Bolotnikova ${ }^{2}$ - Morteza Daneshmand ${ }^{2}$. \\ Cagri Ozcinar $^{3} \cdot$ Gholamreza Anbarjafari $^{2,4}$
}

Published online: 26 November 2019

(C) Springer Science+Business Media, LLC, part of Springer Nature 2019

\section{Correction to: Multimedia Tools and Application (2018) 77:30939-30968 https://doi.org/10.1007/s11042-018-6118-y}

After the publication of this work [1], it was noticed that the co-author Pejman Rasti was omitted as the first author following an institutional investigation. The first author's name is inserted in this erratum article.

The online version of the original article can be found at https://doi.org/10.1007/s11042-018-6118-y

Gholamreza Anbarjafari

shb@icv.tuit.ut.ee

Pejman Rasti

pejman.rasti@univ-angers.fr

Iiris Lüsi

iiris@icv.tuit.ut.ee

Anastasia Bolotnikova

nana@icv.tuit.ut.ee

Morteza Daneshmand

md@icv.tuit.ut.ee

Cagri Ozcinar

ozcinarc@scss.tcd.ie

1 University of Angers, LARIS, UMR INRA IRHS, 62 avenue Notre Dame du Lac, Angers 49000, France

2 iCV Research Lab, Institute of Technology, University of Tartu, 50411 Tartu, Estonia

3 School of Computer Science and Statistics, Trinity College Dublin, Dublin 2, Ireland

4 Department of Electrical and Electronic Engineering, Hasan Kalyoncu University, Gaziantep, Turkey 


\section{Reference}

1. Lüsi I, Bolotnikova A, Daneshmand M et al (2018) Optimal image compression via block-based adaptive colour reduction with minimal contour effect. Multimed Tools Appl 77:30939-30968. https://doi. org/10.1007/s11042-018-6118-y

Publisher's note Springer Nature remains neutral with regard to jurisdictional claims in published maps and institutional affiliations. 